Tropical Journal of Pharmaceutical Research June 2019; 18 (6): 1185-1190

ISSN: $1596-5996$ (print); 1596-9827 (electronic)

(C) Pharmacotherapy Group, Faculty of Pharmacy, University of Benin, Benin City, 300001 Nigeria.

\title{
Interaction between green tea and perindopril reduces inhibition of angiotensin-converting enzyme activity
}

\author{
Norsyahida Mohd Fauzi, Endang Kumolosasi, Malina Jasamai, Norazrina Azmi \\ Drug and Herbal Research Centre, Faculty of Pharmacy, Universiti Kebangsaan Malaysia, Jalan Raja Muda Abdul Aziz, 50300 \\ Kuala Lumpur, Malaysia
}

*For correspondence: Email: e_kumolosasi@ukm.edu.my; Tel: +60392898054; Fax: +60-326983271

Sent for review: 20 July 2018

Revised accepted: 18 May 2019

\begin{abstract}
Purpose: To investigate the blood pressure-lowering effect of green tea (GT) extract alone and in combination with an angiotensin converting enzyme (ACE) inhibitor, perindopril, on rats.

Methods: The study consisted of four groups of five spontaneously hypertensive rats (SHR): negative control (2 \% tragacanth mucilage), positive control group (perindopril, $0.36 \mathrm{mg} / \mathrm{kg} / \mathrm{day}$ ) and two treatment groups (green tea, $25 \mathrm{mg} / \mathrm{kg} /$ day; and combined green tea/perindopril). The treatments were given orally for 14 days. Systolic blood pressure was measured before and after treatment using the tail cuff technique. Angiotensin converting enzyme activity in the lung homogenate of the hypertensive rats was determined spectrophotometrically.

Results: Green tea extract significantly reduced the rats' systolic blood pressure $(p<0.05)$ but did not inhibit the angiotensin-converting enzyme. The combination of green tea extract with perindopril also caused a significant decline in blood pressure $(p<0.001)$. However, the green tea extract attenuated the inhibition of the angiotensin-converting enzyme activity by perindopril.

Conclusion: Green tea extract produces anti-hypertensive activity in rats, but its mechanism of action is not via inhibition of angiotensin-converting enzyme. The interaction of GT extract with perindopril results in a reduction of $A C E$ inhibitory activity.
\end{abstract}

Keywords: Anti-hypertensive, Green tea, Camellia sinensis, ACE inhibitor, Systolic blood pressure, Spontaneously hypertensive rats

\begin{abstract}
This is an Open Access article that uses a fund-ing model which does not charge readers or their institutions for access and distributed under the terms of the Creative Commons Attribution License (http://creativecommons.org/licenses/by/4.0) and the Budapest Open Access Initiative (http://www.budapestopenaccessinitiative.org/read), which permit unrestricted use, distribution, and reproduction in any medium, provided the original work is properly credited.

Tropical Journal of Pharmaceutical Research is indexed by Science Citation Index (SciSearch), Scopus, International Pharmaceutical Abstract, Chemical Abstracts, Embase, Index Copernicus, EBSCO, African Index Medicus, JournalSeek, Journal Citation Reports/Science Edition, Directory of Open Access Journals (DOAJ), African Journal Online, Bioline International, Open-J-Gate and Pharmacy Abstracts
\end{abstract}

\section{INTRODUCTION}

Hypertension is one of the significant public health problems worldwide. This disease is prevalent in both developing and developed countries, and is estimated to be the cause for $4.5 \%$ of the global disease burden [1]. Hypertension is one of the risk factors of both cardiovascular diseases and the all-cause comorbidity which eventually lead to mortality [2]. Perindopril as an angiotensin-converting enzyme (ACE) inhibitor is one of the common drugs used to control blood pressure. This drug reduces blood pressure by inhibiting the activity of the angiotensin-converting enzyme that plays a role in the generation of a vasoconstrictive substance known as angiotensin II [3]. 
Tea is one of the important sources of dietary antioxidants and is the most consumed beverage globally. Green tea (GT), oolong tea and black tea are the basic forms of tea products that are manufactured from different degrees of fermentation of the Camellia sinensis leaves. Camellia sinensis is of the genus Camellia of the flowering plants in the family Theaceae. Among the three products, GT is the least fermented form of tea [4]. Flavonoids, particularly catechins such as epigallocatechin gallate (EGCG), epigallocatechin (EGC), epicatechin gallate (ECG), and epicatechin (EC) from GT are responsible for the various therapeutic effects of GT including antihypertensive [5], antiinflammatory [6], and antioxidant [7]. Previous studies have demonstrated that green tea and its bioactive compound, EGCG, can inhibit ACE activity in endothelial cells [8]. GT was also shown to cause the inhibition of ACE activity in healthy humans [9]. However, little is known on whether green tea can inhibit ACE activity in hypertensive rats.

Green tea has been used to treat hypertension since the ancient times, and the method remains popular in many societies nowadays. Therefore, the likelihood of the concomitant use of GT and prescribed anti-hypertensive drugs is thought to be increasing. For instance, GT extract and EGCG have been shown to be able to interfere with an antihypertensive drug, nadolol through the inhibition of organic anion-transporting polypeptides (OATP)-mediated nadolol uptake [10]. However, less is known about the effect of green tea when it is used in combination with ACE inhibitor. Therefore, the aim of this study is to investigate whether green tea extract can reduce blood pressure through the inhibition of ACE activity in hypertensive rats as well as to evaluate the interaction between green tea and perindopril in spontaneously hypertensive rats (SHR).

\section{EXPERIMENTAL}

\section{Chemicals and equipment}

All chemicals were obtained from Sigma unless stated otherwise. A perindopril tablet $4 \mathrm{mg}$ was purchased from CCM Pharmaceutical, Malaysia. Methanol, sodium hydroxide, sodium chloride and ethyl acetate were obtained from Merck, Germany. The reference standards K0133 kaempferol $\geq 90 \%$ (HPLC) and Q4951 quercetin $\geq 95 \%$ (HPLC) were obtained from Sigma. HEPES sodium salt, hippuryl-L-histidyl-L-leucine $(\mathrm{HHL})$, angiotensin converting enzyme and hippuric acid (HA) were also obtained from Sigma Aldrich (St. Louis). Equipment used in the experiment were a weighing machine (Segatec, Malaysia), ML125 NIBP Controller (AD Instruments Pty. Ltd., US), PowerLab 4/30 (AD Instruments Pty Ltd, US). The HPLC workstation (Waters, Ireland), and Shimadzu UV1800 UV VIS spectrophotometer.

\section{Preparation of methanol GT extract}

The GT leaves were purchased from a food and beverage department in Kuala Lumpur, Malaysia. The brand of the green tea leaves purchased is Ujinotsuyu and the name of the product is Aoyanagi Green. The green tea was in loose tea leaves form and the type of green tea used was Bancha. In the extraction process, the loose tea leaves were soaked in $99.5 \%$ methanol with the ratio of one part of plant to five parts of methanol for three days at room temperature with occasionally shaking. The extracted tea leaves were filtered and the ethanol extract obtained was further processed. The excess solvent in the extract was removed through distillation and further dried at a temperature not exceeding 40 ${ }^{\circ} \mathrm{C}$ in a rotary evaporator. The plant material residues were subjected to another two times of maceration. The extract was kept in refrigerator at $4{ }^{\circ} \mathrm{C}$ throughout the study. Phytochemical screening was performed according to screening methodology as described in Malaysian Herbal Monograph, Volume II (2009) [11].

\section{Phytochemical screening of GT extract}

Phytochemical screening of the crude extracts for a variety of chemical constituents including alkaloids, triterpenes, steroids, saponins, phenolics and flavonoids was carried out using the standard methods [12]. The standard method for alkaloid determination uses the Mayer's reagent, for sterols and triterpenes, using chloroform, sulphuric acid and ethanol respectively; for saponins using the foaming test; and for tannin and flavonoids, using $10 \%$ sodium chloride, $5 \%$ ferric chloride and $20 \%$ sodium hydroxide, $1 \%$ hydrochloride respectively.

\section{Analysis of GT extract}

The GT extract was standardized for quality using high performance liquid chromatography (HPLC) and compared with the reference standards namely kaempferol and quercetin. A chromatographic analysis of the extract and the standard compounds was performed using a reverse-phase HPLC system (Waters, Milford, MA, USA) equipped with the Water Breeze System. The separations were performed using XBridge $^{\mathrm{TM}} \mathrm{C} 18$ column $(4.60 \times 250 \mathrm{~mm}$; particle diameter, $5 \mu \mathrm{m}$; Thermo Scientific, U.S). The 
mobile phase for kaempferol consisted of $0.05 \%$ orthophosphoric acid and acetonitrile at a ratio of $1: 1(\mathrm{v} / \mathrm{v})$ [13], while for quercetin its mobile phase consisted of methanol: acetonitrile: deionized water at a ratio of $3: 1: 1 \mathrm{v} / \mathrm{v} / \mathrm{v}$. The flow rate of the mobile phase was set at $0.3 \mathrm{~mL} / \mathrm{min}$ with 20 $\mu \mathrm{L}$ of injection volume [14]. The detection of kaempferol and quercetin was achieved at 360 $\mathrm{nm}$ and $262 \mathrm{~nm}$, respectively. The HPLC method was validated through the determination of linearity, precision, limits of quantification (LOQ) and detection (LOD).<smiles>O=c1c(O)c(-c2ccc(O)cc2)oc2cc(O)cc(O)c12</smiles>

Figure 1: Structure of kaempferol<smiles>O=c1c(O)c(-c2ccc(O)c(O)c2)oc2cc(O)cc(O)c12</smiles>

Figure 2: Structure of quercetin

\section{Animal studies}

The procedures performed on spontaneously hypertensive rats (SHR) and Sprague Dawley rats were approved by the ethics committee of Universiti Kebangsaan Malaysia (approval no. FF/2013/NORSYAHIDA/15-MAY/517-JUNE2013-JAN.-2014), and the study was in accordance with international guidelines for animal studies [15].

The male SHRs hypertensive rat model and male Sprague Dawley rats (as normal control) were purchased from the Animal House of University Science Malaysia, Kelantan, Malaysia. Rats with body weight between 200 to $250 \mathrm{~g}$ were chosen and subjected to a week of acclimation period. The rats were caged individually in a temperature-controlled room at $27{ }^{\circ} \mathrm{C}$ under a 12-h artificial light and dark cycle and were given rat pellets and tap water ad libitum.

SHRs were randomly divided into four groups of five rats per group. The groups were administered with tragacanth $1 \%$ group as vehicle control, perindopril suspension (0.36 $\mathrm{mg} / \mathrm{kg} /$ day), GT extract (25 mg/kg/day), and a combination of GT extract and perindopril suspension respectively. The treatment was given orally for consecutive 14 days. At the end of the treatment, the rats' blood pressure was measured. Next, the rats were sacrificed and lungs were immediately removed, washed with ice-cold $10 \mathrm{mmol} / \mathrm{L}$ potassium phosphate buffer $(\mathrm{pH}$ 8.3), weighed, and prepared for the determination of ACE activity.

\section{Measurement of systolic blood pressure (SBP)}

The SBP was measured prior to drug administration and after two weeks of drug administration using the tail cuff method. The rats were restrained in plastic strainer and heated to $28-30{ }^{\circ} \mathrm{C}$ for 5 mins to detect the pulsation of the tail artery. A cuff with a pneumatic pulse sensor was attached to the rats and the blood pressure was collected using a data acquisition system (ML125 NIBP Controller and PowerLab 4/30, AD Instruments Pty Ltd, US).

\section{Measurement of ACE activity}

The ACE activity was measured using the modified method of Nakamura et al [16]. In brief, the collected lung samples were diced and homogenized in ice-cold phosphate buffer. The homogenate was centrifuged at $5000 \times \mathrm{g}$ for 10 mins and the supernatant fluid was dialyzed for $24 \mathrm{~h}$ against $20 \mathrm{~mL}$ of the same buffer at $4{ }^{\circ} \mathrm{C}$. A dialyzed sample $(50 \mu \mathrm{L})$ was added to the $\mathrm{HHL}$ $(200 \mu \mathrm{L}$ of $5 \mathrm{mmol} / \mathrm{L} \mathrm{HHL}$ ) and preincubated at $37^{\circ} \mathrm{C}$ for $30 \mathrm{~min}$. The reaction was initiated by adding the ACE from the rabbit lung $(20 \mu \mathrm{L}$ of 0.1 $\mathrm{U} / \mathrm{mL}$ ) and incubating it for 30 minutes at $37^{\circ} \mathrm{C}$; and the reaction was stopped using $\mathrm{HCl}(250 \mu \mathrm{l}$, $0.05 \mathrm{~mol} / \mathrm{L} \mathrm{HCl}$ ). The liberated HA was extracted using ethyl acetate $(2 \mathrm{~mL})$. The upper ethyl acetate layer was taken out and evaporated at $95{ }^{\circ} \mathrm{C}$ for $10 \mathrm{~min}$. The HA was dissolved in distilled water $(1 \mathrm{~mL})$ and the absorbance of the solution was measured at $228 \mathrm{~nm}$ using a UVvisible spectrophotometer. Commercial HA was used as standard. The increase in the concentration of hippuric acid formation catalyzed by the ACE is associated with the increased in ACE activity.

\section{Statistical analysis}

Statistical analysis was performed using Prism (version 5) software. All values including the SBP and concentration of $\mathrm{HA}$ were expressed as mean \pm SEM. Differences in the measured values in different groups were analyzed using one-way ANOVA followed by Bonferoni's multiple comparison tests. $P<0.05$ or 0.001 was 
considered as statistically significant, as appropriate.

\section{RESULTS}

\section{Phytochemical profile of GT extract}

The GT extract showed the presence of various phytochemicals including alkaloids, triterpenes/steroid, flavonoids, saponins and tannins. The phytochemical characteristics of the GT extract are summarized in Table 1.

Table 1: Phytochemical profile of GT extract

\begin{tabular}{lc}
\hline Phytochemical compound & GT extract \\
\hline Alkaloids & + \\
Triterpenes/ Steroids & + \\
Saponins & + \\
Phenolics/ Tannins & + \\
Flavonoids & +
\end{tabular}

The presence of phytochemicals was detected using tests for alkaloids, triterpenes/steroids, saponins, phenolics/tannins and flavonoids. (+) indicates the presence of the phytochemicals in the extract. GT: green tea extract

\section{Chromatographic profile of GT extract}

Table 2 shows a standardization of the GT extract using HPLC analysis. The kaempferol and quercetin calibration curves plotted were linear over the concentration range of 13 to 200 $\mu \mathrm{g} / \mathrm{mL}$ with a correlation coefficient $\left(r^{2}\right)$ of 0.9878 and 31 to $500 \mu \mathrm{g} / \mathrm{mL}$ with a correlation coefficient $\left(r^{2}\right)$ of 0.9961 .

\section{Effect of GT extract alone and in combination with perindopril on SBP}

Firstly, it was found that the GT extract reduced the systolic blood pressure of hypertensive rats, and the effect is comparable to the conventional antihypertensive drug, perindopril. Blood pressure in this study was determined by comparing the reduction of SBP between different groups. Figure 3 shows the effect of vehicle control, perindopril, GT extract alone and GT extract plus perindopril on the SBP of hypertensive rats after 14 days of treatment. The GT extract $(25 \mathrm{mg} / \mathrm{kg}$ ) significantly reduced SBP $(p<0.05)$ by $12.634 \pm 4.06 \mathrm{mmHg}$ when compared to vehicle control, whilst perindopril $(0.36 \mathrm{mg} / \mathrm{kg})$ lowered SBP by $23.11 \pm 4.08$ $\mathrm{mmHg}(p<0.001)$. No significant reduction of blood pressure was found between green tea extract versus perindopril at the concentration used in this study. A combination of these agents was initially hypothesized to cause a synergistic effect on reduction of blood pressure. Although the GT extract and perindopril caused a reduction in SBP individually, they showed no synergistic effect in reducing blood pressure when used in combination (22.04 $\pm 2.84 \mathrm{mmHg}$ ) $(p<0.001)$ compared to the vehicle control group.

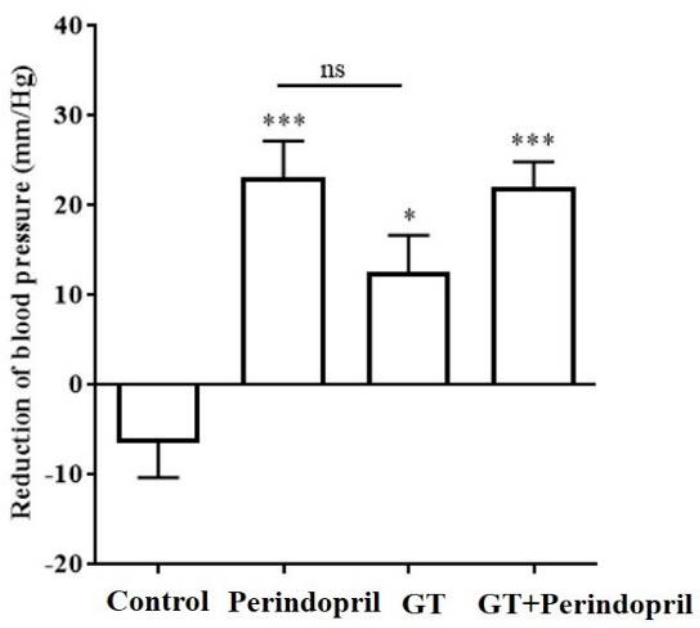

Figure 3: Effect of green tea alone and in combination with perindopril on systolic blood pressure of spontaneously hypertensive rats. Data were expressed as mean \pm standard error mean (SEM) for $\mathrm{n}=5$ observations. GT: green tea extract; ${ }^{*} p<0.05$ and ${ }^{* * *} p<0.001$, significantly different compared to vehicle control.

\section{Effect of GT extract alone and in combination with perindopril on ACE activity}

Figure 4 shows that green tea did not reduce the hippuric acid level produced by the ACE of rats treated with GT extract (18.28 $\pm 1.04 \mu \mathrm{g} / \mathrm{mL})$. Perindopril alone significantly reduced $(p<$ $0.001)$ the hippuric acid level (7.18 \pm 0.65 $\mu \mathrm{g} / \mathrm{mL})$. This finding showed that the decrease in SBP by the GT extract is not through ACEl pathway.

Table 2: Standardization of green tea extract

\begin{tabular}{lccc}
\hline Compound & $\begin{array}{c}\text { Retention time of } \\
\text { standards }(\mathbf{m i n})\end{array}$ & $\begin{array}{c}\text { Retention time of compounds } \\
\text { in the GT extract }(\mathbf{m i n})\end{array}$ & $\begin{array}{c}\text { Concentration of compounds in } \\
\text { the GT extract }(\mathbf{m g} / \mathbf{g})\end{array}$ \\
\hline Kaempferol & 14.750 & 14.280 & 3.10 \\
Quercetin & 2.732 & 2.618 & 0.8 \\
\hline
\end{tabular}

Note: Extract was standardized using HPLC analysis and compared with the reference standards, kaempferol and quercetin 
Interestingly, we found that when perindopril was treated in combination with the GT extract, the hippuric acid level had increased (16.06 \pm 0.16 $\mu \mathrm{g} / \mathrm{mL}$, Figure 4), suggesting that the GT extract might have a drug-herbal interaction where it can reduce the inhibition of ACE activity by perindopril.

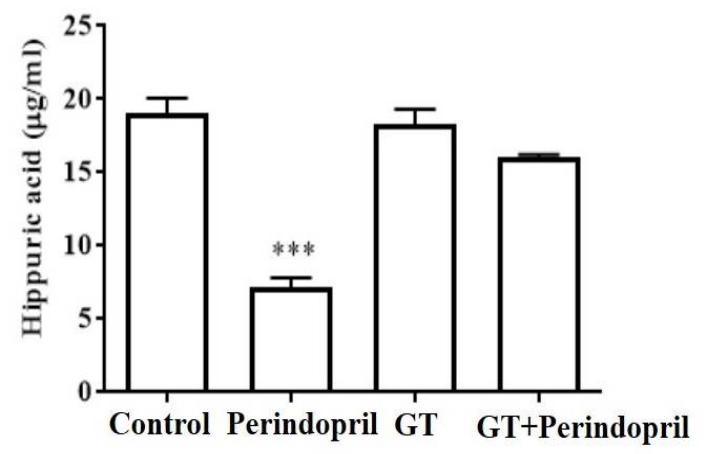

Figure 4: Effect of green tea alone and in combination with perindopril on the hippuric acid level in the ACE activity test on the from lung homogenate of spontaneously hypertensive rats. Data were expressed as mean \pm standard error mean (SEM) for $\mathrm{n}=5$ observations. GT: green tea extract; ${ }^{*} p<0.05$ and ${ }^{* * *} p<0.001$, significantly different when compared to vehicle control

\section{DISCUSSION}

Green tea extract shows a comparable effect versus perindopril in the reduction of blood pressure. This is in agreement with several studies with regard to the ability of green tea extract to reduce blood pressure. For example, it was found that decaffeinated GT extract reduces SBP in rat models with the metabolic syndrome [17]. Flavonoids, particularly catechins play an important role in the GT-mediated blood pressure lowering effect. Epigallocathecin gallate (EGCG), one of the main active flavonoids in green tea was shown to be responsible for the reduction of blood pressure in hypertensive rats [18]. Phytochemical screening carried out in the present study indicate the presence of flavonoids in green tea extract, supporting the evidence that flavonoids are the major compounds that causes the blood lowering effect of GT.

Reduction of BP by GT has been reported to occur through various mechanisms, particularly through the inhibition of ACE activity. Several studies have suggested that the GT's antihypertensive activities may be mediated through the inhibition of ACE. For example, green tea extract and its active components including (-)-epicatechin, (-)-epigallocatechin, (-)epicatechingallate and (-)-epigallocatechingallate reduced ACE activity in human endothelial cells in a dose dependent manner after 10 min of treatment [8]. Moreover, green tea reduces the ACE activity in healthy human blood after consumption of tea infusion (10 $\mathrm{mg}$ in $400 \mathrm{ml}$ ) at $30 \mathrm{~min}, 1$ and $3 \mathrm{~h}[9]$.

However, in the present study, it was found that the GT extract did not inhibit ACE activity in spontaneously hypertensive rats. The different results observed between our study and previous studies could be due to differences in the condition of ACE activity, that is in normal versus hypertension models. In normal conditions, the ACE activity is lower whilst in hypertensive conditions, the ACE activity tends to be higher. However further investigation has to be carried out to compare the difference in ACE activity between normal and hypertensive models.

The green tea extract did not reduce the hippuric acid level; in contrary, the perindopril reduced the hippuric acid level significantly (Figure 4). Previous work by Sagesaka et al demonstrated that tea-leaf saponin may reduce the blood pressure of SHR and inhibit angiotensin-I induced contraction on guinea pig ileum, however the effect on the inhibition of $\mathrm{ACE}$ activity in vitro is weak $\left(\mathrm{IC}_{50}>10 \mathrm{mg} / \mathrm{mL}\right)$ [19]. Based on this evidence, there is a possibility that the hypotensive effect of the GT extract used in the study could be mediated by its saponin component. Therefore, it is of interest to further investigate whether GT extract can reduce blood pressure through inhibition of angiotensin-1.

\section{CONCLUSION}

The findings of this study demonstrate that GT extract significantly reduces rat SBP but does not inhibit the ACE activity of spontaneously hypertensive rats. Administration of the combination of GT extract and perindopril did not cause a synergistic reduction of blood pressure in rats, but the GT may have interacted with perindopril, resulting in a lowering of $A C E$ inhibitory activity. This finding shows that the use of green tea alone reduces blood pressure, but the use of green tea with perindopril may not have additional therapeutic value.

\section{DECLARATIONS}

\section{Acknowledgement}

The authors thank the Faculty of Allied Science, UKM for the use of tail cuff and a data acquisition system.

\section{Conflict of interest}

Trop J Pharm Res, June 2019; 18(6): 1189 
No conflict of interest is associated with this work.

\section{Contribution of authors}

This work has been carried out by the authors named in this article and all liabilities pertaining to claims relating to the content of this article will be borne by them. NMF and EK were involved in the experimental design. NMF carried out the experiment, collected the data and analyzed it under the supervision of EK and NMF, MJ, NA and EK drafted and finalized the manuscript. All authors read and approved the final manuscript.

\section{Open Access}

This is an Open Access article that uses a funding model which does not charge readers or their institutions for access and distributed under the terms of the Creative Commons Attribution License (http://creativecommons.org/licenses/by/ 4.0) and the Budapest Open Access Initiative (http://www.budapestopenaccessinitiative.org/rea d), which permit unrestricted use, distribution, and reproduction in any medium, provided the original work is properly credited.

\section{REFERENCES}

1. Whitworth JA. World Health Organization (WHO)/International Society of Hypertension (ISH) statement on management of hypertension. $J$ Hypertens 2003; 21: 1983-1992.

2. Zicha J, Kunes J. Ontogenetic aspects of hypertension development: analysis in the rat. Physiol Rev 1999; 9: 1227-1282.

3. Campbell DJ. A review of perindopril in the reduction of cardiovascular events. Vasc Health Risk Ma 2006; 2: 117-124.

4. Graham HN. Green tea composition, consumption, and polyphenol chemistry. Prevent Med 1992; 21: 334-350.

5. Garcia ML, Nishi EE, Lincevicius GS, Veiga GRL, Pontes RB, Campos RR, Oyama L, Bergamaschi CT. Effects of chronic green tea (GT) or green tea extract (GTE) treatment in cardiovascular function in hypertensive rats. FASEB J 2013; 27: 1192-1193.

6. D'dharan SK, Ganapathy D. Medical management of Denture Stomatitis. Asian J Pharm Clin Res 2016; 9: 1416.

7. Moradpourian MR, Ashkavand Z, Venkatesh C, Vishwanath BS. Effect of different doses of green tea on oxidative stress and muscle soreness in downhill treadmill running. Asian J Pharm Clin Res 2014; 7; 192193.

8. Persson IA, Josefsson M, Persson K, Andersson RG. Tea flavanols inhibit angiotensin-converting enzyme activity and increase nitric oxide production in human endothelial cells. J Phar Pharmacol 2006; 58: 11391144.

9. Persson IA, Persson K, Hagg S, Andersson RG. Effects of green tea, black tea and Rooibos tea on angiotensinconverting enzyme and nitric oxide in healthy volunteers. Public Health Nutr 2010; 13: 730-737.

10. Misaka S, Miyazaki N, Fukushima T, Yamada S, Kimura J. Effects of green tea extract and (-)-epigallocatechin-3gallate on pharmacokinetics of nadolol in rats. Phytomed 2013; 20: 1247-1250.

11. Committee Malaysian Herbal Monograph. Malaysian Herbal Monograph 2009; 2: 131-138.

12. Trease GE and Evans WC. Pharmacology 11th Edn, BailliereTindall Ltd., London; 1989.

13. Cupáková MRD, Vitková $Z$, Herdová $P$, Grančai $D$, Haladová M. Determination of kaempferol in extracts from Lilium candidum L. Liliaceae by means of liquid chromatography. Acta Fac Pharm Univ Comen 2012; 59: 14.

14. Krishnareddy NV, Ramesh R. New RP - HPLC method development for analysis and assay of lamivudine in formulation. Int $J$ Res Pharm and Biomed Sci 2011; 4: 2229-3701.

15. WHO Chronicle. A ClOMS Ethical Code for Animal Experimentation Norman Howard-Jones 1985; 39 (2): 51-56.

16. Nakamura Y, Yamamoto $N$, Sakai K, Okubo A, Yamazaki $S$, Takano T. Purification and characterization of angiotensin 1-converting enzyme inhibitors from sour milk. J Dairy Sc 1995; 78: 777-783.

17. Ihm SH, Jang SW, Kim OR, Chang K, Oak MH, Lee JO, Lim DY, Kim JH. Decaffeinated green tea extract improves hypertension and insulin resistance in a rat model of metabolic syndrome. Atherosclerosis 2012; 22: 377-383.

18. Potenza MA, Marasciulo FL, Tarquinio M, Tiravanti E, Colantuono G, Federici A, Kim JA, Quon MJ, Montagnani M. EGCG, a green tea polyphenol, improves endothelial function and insulin sensitivity, reduces blood pressure, and protects against myocardial I/R injury in SHR. Am J Physiol Endocrinol Metab 2007; 292: 1378-1387.

19. Sagesaka-Mitane $Y$, Sugiura T, Miwa $Y$, Yamaguchi $K$, Kyuki K. Effect of tea-leaf saponin on blood pressure of spontaneously hypertensive rats. Pharm Soc Japan 1996; 116: 388-395. 